\title{
Influence of Pinealectomy and Long-term Melatonin Administration on Inflammation and Oxidative Stress in Experimental Gouty Arthritis
}

\section{Arwa Fadıl Haqi BALLUR}

Karabük Üniversitesi Tip Fakültesi: Karabuk Universitesi Tip Fakultesi

Eyup ALTINOZ

Karabük Üniversitesi Tip Fakültesi: Karabuk Universitesi Tip Fakultesi

\section{Gurkan YIGITTURK}

Mugla Sitki Kocman Universitesi Tip Fakultesi

Melike Ozgul Onal

Mugla Sitki Kocman Universitesi Tip Fakultesi

\section{Hulya ELBE}

Mugla Sitki Kocman Universitesi Tip Fakultesi

\section{Yasemin BICER}

Karabük Üniversitesi Tip Fakültesi: Karabuk Universitesi Tip Fakultesi

\section{Melike KARAYAKALI}

Karabük Üniversitesi Tip Fakültesi: Karabuk Universitesi Tip Fakultesi

mehmet demir ( $\square$ mehmetdemir@karabuk.edu.tr)

Karabuk University Faculty of Medicine: Karabuk Universitesi Tip Fakultesi https://orcid.org/00000001-6990-3337

\section{Research Article}

Keywords: Gout, monosodium urate crystals, melatonin, oxidative stress, pinealectomy, rat

Posted Date: December 16th, 2021

DOI: https://doi.org/10.21203/rs.3.rs-1162095/v1

License: (c) (i) This work is licensed under a Creative Commons Attribution 4.0 International License. Read Full License

Version of Record: A version of this preprint was published at Inflammation on January 18th, 2022. See the published version at https://doi.org/10.1007/s10753-022-01623-2. 


\section{Abstract}

Gout is an inflammatory arthritis characterized by the deposition of monosodium urate (MSU) crystals in the joints or soft tissue. MSU crystals are potent inflammation inducers. Melatonin (MLT) is a powerful endogenous anti-inflammatory agent and effective in reducing cellular damage. In the present study, possible underlying mechanisms associated with anti-inflammatory and anti-oxidative effects were investigated in rats with gouty arthritis and melatonin deprivation treated with MLT. Fifty-six rats were divided into seven groups: control, sham control, pinealectomy (PNX), MSU (On the 30th day, single dose $20 \mathrm{mg} / \mathrm{ml}$, intraperitoneal), MSU+MLT (10 mg/kg/day for 30 days, intraperitoneal), MSU+PINX and MSU+PINX+MLT. PNX procedure was performed on the first day of the study. As compared to the controls, the results showed that MSU administration caused significant increases in oxidative stress parameters (malondialdehyde and total oxidant status). Besides, significant decreases in antioxidant defense systems (glutathione, superoxide dismutase and total antioxidant status were observed. A statistically significant increase was found in the mean histopathological damage score in the groups that received MSU injection. It was found that histopathological changes were significantly reduced in the MSU+MLT group given MLT. In our study, it was determined that many histopathological changes, as well as swelling and temperature increase in the joint, which are markers of inflammation, were significantly reduced with MLT supplementation. These results suggest that melatonin ameliorates MSU-induced gout in the rat through inhibition of oxidative stress and proinflammatory cytokine production.

\section{Introduction}

Gout is a metabolic disease characterized by high serum urate level (hyperuricemia) triggered by purine catabolic pathway disorders [1], leading to the accumulation of monosodium urate (MSU) crystals in synovial joints and tissues [2]. The incidence and prevalence of gout are rising globally in recent years, imposing great disease burden worldwide [3]. Gout could be classified as primary and secondary gout. Primary gout is the most common type observed without any underlying disease that could lead to hyperuricemia. Secondary gout is a less common form exacerbated by the effects of genetic enzymatic defects, obesity, chemotherapy, alcohol poisoning and immunosuppressants [4]. Hyperuricemia could result due to hepatic overproduction of uric acid and/or inadequate excretion of urate in the small intestine and kidneys [5]. Hyperuricemia and gout prevalence has been increasing worldwide due to lifestyle changes, obesity, consumption of purine-rich nutrients, beverages with fructose, and spirits [6]. Increase in serum urate concentrations (hyperuricemia, $\geq 7.0 \mathrm{mg} / \mathrm{dL}$ ) is manifested in the inflammation induced by the deposition of MSU crystals in cartilage, synovial bursa, tendons, or soft tissues [7]. It is currently accepted that the accumulation of crystallized MSU in the joints is a central risk factor for gout [8]. MSU crystals are potent inflammation inducers. These crystals stimulate a local inflammatory reaction within the joint, neutrophil recruitment, and the production of pro-inflammatory cytokines as well as other inflammatory mediators [9].

Melatonin (MLT) is an indolamine derived from the essential amino acid tryptophan via serotonin [10]. The main production site is the pineal gland located in the brain [11]. Circadian rhythms play a key role in 
the development of physiological and pathological responses based on daily environmental variations [12]. MLT is released to regulate the circadian rhythm, and has anti-inflammatory [13], antitumor and antiapoptotic effects [14]. Furthermore, MLT is a powerful antioxidant that reduces oxidative stress due to its capacity to directly scavenge reactive species and modulate the antioxidant defense system by increasing antioxidant enzyme activities [15].

Recent studies demonstrated that several factors, including MLT, play a role in the regulation of the rhythmic migration of neutrophils. However, the mechanisms underlying the regulation of the rhythmic neutrophil migration by endogenous MLT remain unclear [16]. In the pineal gland, where MLT is produced, changes associated with age such as decreased pinealocyte count, increased calcification, and decreased MLT production were observed [17]. Gout prevalence has increased in elderly population [18]. Oxidative stress is an important factor for aging. The antioxidant catalase (CAT) and superoxide dismutase (SOD) enzymes and the endogenous antioxidant glutathione (GSH) significantly protect the organism against the oxidative stress associated with age. [19].

In the present study, an experimental MSU crystal-induced rat model was set up to investigate the potential effects of MLT on gouty arthritis and gouty arthritis induced by melatonin deprivation. In the study, possible underlying mechanisms associated with anti-inflammatory and anti-oxidative effects were also investigated in rats with gouty arthritis and melatonin deprivation treated with MLT.

\section{Material And Methods}

The study was conducted on 56 male Wistar Albino rats that weighed $250-300 \mathrm{~g}$. Rats were divided into 7 groups $(n=8)$. During the experiments, animals were kept in an environment under $21 \pm 1^{\circ} \mathrm{C}$ temperature and 12 hours of light and 12 hours of dark, and ad libitum standard rat chow and regular tap water were provided.

The study was approved by Zonguldak Bülent Ecevit University Faculty of Medicine Experimental Animals Ethics Committee (Protocol No: 2020-10-07/05). All experimental procedures were conducted in accordance with the Animal Ethics Committee Guidelines for experimental animals.

\section{Preparation and Injection of Melatonin (MLT) Solution}

MLT was dissolved in $0.5 \%$ ethanol $(0.5 \%)$ and adjusted to the adequate concentration with physiological saline solution. The final concentration of ethanol in the solution was set to $0.5 \%$ [20]. Based on the study group, $10 \mathrm{mg} / \mathrm{kg} /$ day i.p. MLT or MLT solution was administered for 30 days.

\section{Preparation and Injection of Monosodium Urate (MSU) Crystals}

MSU crystals $(20 \mathrm{mg} / \mathrm{ml})$ were prepared as $50 \mu \mathrm{L}$ sterile phosphate buffer solution (PBS). Rats were anesthetized with $80 \mathrm{mg} / \mathrm{kg}$ i.p. ketamine (Ketalar-Eczacıbaşı/Turkey) and $8 \mathrm{mg} / \mathrm{kg}$ xylazine (Rompun- 
Bayer/Turkey) [21]. After the anesthesia, $50 \mu \mathrm{L}$ PBS MSU was injected into the medial side of the left tibiotarsus joint.

\section{The Pinealectomy Procedure}

An incision was applied on the scalp, equidistant from the two eyes of the anesthetized rats, between the back of the nose and the nape. The periosteum was stripped to reveal the lambda. A circular incision was applied in the upper part of the skull with a micro milling drill (Proxxon MICROMOT 50/E, Germany) to accommodate the access of forceps tip. The pineal gland located under the venous sinus was removed massively with the forceps. Then, the removed bone piece was replaced, the scalp was sutured, and $10 \%$ povidone iodine was applied.

\section{Study design}

Rats were separated into 7 groups of 8 animals each as follows.

\section{Control group}

No application was conducted in this group.

\section{Sham Pinealectomy (PINX) group}

The rats in this group underwent sham PINX on the first day of the experiment. Intraperitoneal (i.p.) $0.9 \%$ saline (MLT solvent) injection was administered for 30 days after the first day, and a single intra-articular (i.a.) $50 \mu \mathrm{l}$ phosphate buffer solution (PBS; MSU solvent) injection was administered on the 30 th day of the study.

\section{Monosodium urate (MSU) (Model) group}

MLT solvent was administered intraperitoneally to the rats in this group for 30 days. On the 30th day, single dose $20 \mathrm{mg} / \mathrm{ml} \mathrm{MSU}$ was administered in $50 \mu \mathrm{L}$ of sterile PBS [22].

\section{MSU+MLT group}

The rats in this group were administered $10 \mathrm{mg} / \mathrm{kg} /$ day MLT i.p. for 30 days [23]. On the 30th day, single dose $50 \mu \mathrm{MSU}$ was injected i.a.

\section{PINX group}

The rats in this group underwent PINX procedure on the first day of the study.

\section{PINX+MSU group}

The rats in this group underwent PINX on the first day of the study. MLT solution was administered intraperitoneally for 30 days. On the 30 th day, single dose $50 \mu \mathrm{MSU}$ was injected i.a. 


\section{PINX+MSU+MLT group}

The rats in this group underwent PINX procedure on the first day of the study. MLT solution was administered intraperitoneally for 30 days. On the 30th day, single dose $50 \mu \mathrm{MSU}$ was injected i.a.

On the 30th day of the study, the circumference of the ankle joint was measured with a digital caliper in all groups. Edema in the ankle was determined based on the increase in ankle circumference [24]. 24 hours after the induction of gout (determined based on the ankle circumference measurements), rats were decapitated, and blood and joint tissue samples were collected. Malondialdehyde (MDA) level, an end product of lipid peroxidation, and reduced glutathione (GSH) level, an endogenous non-enzymatic antioxidant, and superoxide dismutase (SOD) and catalase (CAT) antioxidant enzyme activities were determined in blood serum. Furthermore, histopathological evaluation of the joint tissues was conducted.

\section{The analysis of ankle circumference and joint skin temperature changes}

After all applications were conducted (on day 30), the circumference of the left tibiotarsal joint of each rat was measured with a digital caliper after $0,2,8,16$ and 24 hours. Similarly, the joint temperatures of these rats were measured with a precision thermometer.

\section{Histopathological evaluation}

After the procedures, the rats were sacrificed with ketamine/xylazine anesthesia. The heart tissue samples were fixed in $10 \%$ neutral formalin buffer. Tissues were washed in running water and demineralized in $10 \%$ ethylenediaminetetraacetic acid (EDTA) solution with a $7.4 \mathrm{pH}$ for $\sim 4$ weeks at room temperature (mean temperature: $28^{\circ} \mathrm{C}$ ). In EDTA samples, the solution was replaced every 2 or 3 days. Then, the tissues were dehydrated with increasing ethanol concentrations (50\%, 75\%, 96\% and $100 \%)$. Then, the samples $w$ ere transferred into xylene to achieve transparency and embedded in paraffin. Six $6 \mu \mathrm{m}$ paraffin blocks were incised, mounted on slides, and stained with hematoxylin and eosin $(\mathrm{H}-\mathrm{E})$. The tissue sections were examined with light microscopy. The parameters evaluated for severity of articular damage included cartilage destruction, inflammation, and bone erosion in 10 microscopic fields in each section. Histopathologic findings were analyzed with grading scales, as described above [25]. Cartilage destruction and bone erosion were graded based on a scale between 0 and 3 , where 0 depicted no change, 1 depicted identifiable changes, 2, moderate changes at few sites, and 3 , severe cartilage destruction and bone erosion. Inflammation was also graded on a $0-3$ scale, where 0 reflected no cells with inflammation, 1, low increase in inflammatory cell count, 2, moderate increase in inflammatory cell count, and 3 , severe increase in inflammatory cell count. All sections were examined with a Nikon Eclipse 80i light microscope and Nikon Image Analysis system (Tokyo, JAPAN).

\section{Statistical analysis}

Statistical analysis was conducted with the SPSS for Windows v. 14.0 (SPSS Inc., Chicago, III., USA) statistics software. All data are given in arithmetic mean \pm SE. The normal distribution of continuous 
variable data was determined with the Shapiro Wilk test. The variables did not exhibit normal distribution $(p<0.05)$. Kruskal-Wallis and Mann-Whitney $U$ tests were employed to compare the variables in the groups. $p<0.05$ was considered significant.

\section{Biochemical Analysis}

After the anesthesia, blood samples were collected from the abdominal vein via laparotomy and the animals were decapitated. The blood samples were stored at room temperature for about one hour for coagulation, and then the serum samples were obtained with centrifugation at $4000 \mathrm{rpm}$ for 20 minutes. After the serum samples were separated into Eppendorf tubes, they were stored in a deep freezer at $-80^{\circ} \mathrm{C}$ for biochemical tests.

\section{Preparation of the Samples}

The malondialdehyde (MDA), reduced glutathione (GSH), superoxide dismutase (SOD), catalase (CAT) analyses were conducted on the samples, and total antioxidant (TAS), total oxidant (TOS) levels, oxidative stress index (OSI), interleukin-6 (IL-6) and protein levels were determined.

\section{Measurement of Serum Malondialdehyde (MDA) Level}

Serum MDA analysis was conducted based on the method described by Ohkawa et al. [26]. After the serums were mixed with $1 \% \mathrm{H}_{3} \mathrm{PO}_{4}$ and $0.6 \%$ thiobarbituric acid in a plugged glass tube, they were incubated in a boiling water bath for 45 minutes after the tube plugs were tightly wrapped with aluminum foil. Then, the mixture was extracted with n-butanol, and the pink color separated in the n-butanol phase with centrifuge and placed in microplate wells based on the study groups and measured at $535 \mathrm{~nm}$ wavelength in an ELISA reader to determine the MDA level. N-butanol was employed as the blank, and tetramethoxypropane was used as the standard. The findings are presented in $\mu \mathrm{mol} / \mathrm{L}$.

\section{Measurement of Serum Reduced-Glutathione (GSH) Level}

Serum reduced glutathione (GSH) analysis was conducted with the method described by Ellman [27]. After the serums were deproteinized, they were reacted with 5,5'-dithiobis 2-nitrobenzoic acid (DTNB) in an Eppendorf tube and incubated to form a yellow-green color. The colored product was placed on microplates based on the study group and measured at a wavelength of $410 \mathrm{~nm}$ in an ELISA reader to determine the GSH level. Different dilutions prepared with distilled water was used as blank and $5 \mathrm{mM} / \mathrm{L}$ stock GSH solution was used as standard. Results are presented in $\mu \mathrm{mol} / \mathrm{L}$.

\section{Measurement of Serum Superoxide Dismutase (SOD) Enzyme Activity}

Serum SOD activities were determined with the method developed by Sun et al. [28]. Superoxide radicals are formed by the xanthine-xanthine oxidase reaction in the experimental medium. These radicals lead to a blue formazan by reducing NBT (nitro blue tetrazolium). Serum SOD activities were determined based on the measurement of this blue-colored formazan at $560 \mathrm{~nm}$ in an ELISA reader. The results are presented in $\mathrm{U} / \mathrm{g}$ protein. 


\section{Measurement of Serum Catalase (CAT) Enzyme Activity}

Serum CAT activities were determined with the method proposed by Aebi et al. [29]. The supernatant and $\mathrm{H}_{2} \mathrm{O}_{2}$ phosphate buffer $(\mathrm{pH}: 7.5 \mathrm{mM})$ were mixed in the experiment medium. $\mathrm{H}_{2} \mathrm{O}_{2}$ is broken down to $\mathrm{H}_{2} \mathrm{O}$ and $\mathrm{O}_{2}$ due to serum CAT activity. Degradation of hydrogen peroxides in the medium leads to a decrease in absorbance at $240 \mathrm{~nm}$. The decrease in absorbance was observed for $1 \mathrm{~min}$ to calculate the CAT activity. Results are presented in $\mathrm{K} / \mathrm{g}$ protein.

\section{Measurement of Serum Protein Level}

To calculate the serum SOD and CAT enzyme activities, the protein levels were determined with the method published by Lowry et al. [30]. The resulting blue color was measured with an ELISA reader at 700 $\mathrm{nm}$ wavelength to calculate the protein content. Results are presented in $\mathrm{mg} / \mathrm{ml}$.

\section{Measurement of Serum Total Oxidant Status (TOS)}

Serum TOS was measured with the Erel's method [31]. Total oxidant status was determined based on the kit procedure (Rel Assay Diagnostics, Gaziantep Turkey). The colored compounds were measured with an ELISA reader at $530 \mathrm{~nm}$ wavelength to calculate the serum TOS. $20 \mu \mathrm{mol} / \mathrm{L} \mathrm{H}_{2} \mathrm{O}_{2}$ solution was used as the standard. Results are presented in $\mu$ mol $\mathrm{H}_{2} \mathrm{O}_{2}$ equiv./L.

\section{Measurement of Serum Total Antioxidant Status (TAS)}

Serum TAS was determined with the Erel's method [31]. Total antioxidant status was determined with the kit procedure (Rel Assay Diagnostics, Gaziantep, Turkey). Reagent 1 was added to the supernatant placed on microplates as per the kit instructions, and first reading was conducted at $660 \mathrm{~nm}$, and the second reading was conducted after the reagent 2 was added. The difference between the two absorbances was determined to calculate the serum TAS. Trolox, a water-soluble analog of vitamin E, was used as the calibrator. Results are presented in mmol Trolox equiv./L.

\section{Measurement of Serum Oxidative Stress Index (OSI)}

Serum OSI was calculated with the Erel's method [31]. OSI equals TOS divided by TAS: OSI (Arbitrary Unit) $=$ TOS $\left(\mu \mathrm{mol} \mathrm{H}_{2} \mathrm{O}_{2}\right.$ eqv/1) / TAS (mmol Trolox eqv/l) x 10. The findings are reported in arbitrary units (AU). Measurement of Serum IL-6 Level

Serum IL-6 levels were determined with the Rat ELISA kit (Cat. No E0135Ra) purchased from Bioassay Technology Laboratory (BT Lab, CHINA) based on the kit protocol and the results are presented in $\mathrm{pg} / \mathrm{ml}$.

\section{Results}

\section{The effects of MLT on MSU crystal-induced ankle circumference and skin temperature in rats}


Since the increases in temperature and swelling in joints and periarticular regions are the most common symptoms of gout, we first investigated whether melatonin could prevent these symptoms caused by MSU. The circumference of the knee joint was measured $0,2,8,16$, and 24 hours after the intra-articular MSU injection. The comparison of MSU-injection groups and the other groups revealed a significant increase in ankle circumference (Fig. 1).

In particular, increases in ankle circumference and skin temperature in the above-mentioned region were identified after 2 hours in MSU group rats without MLT treatment ( $<<0.001)$. (Fig. 2 and Fig. 3). However, the ankle circumference and joint skin temperature of the rats with MLT treatment (MSU+MLT and MSU+PINX+MLT groups) before MSU injection did not increase due to MLT treatment (Fig. 2 and Fig. 3). MLT treatment prevented MSU crystal-induced inflammation.

\section{Comparison of serum MDA and GSH between the groups}

PINX application to experimental animals (PINX group) led to significant increases in MDA levels when compared to control and SHAM groups $(p<0.001)$, while significant decreases $(p<0.001)$ were observed in GSH levels (Fig. 4). Furthermore, MSU injection (MSU group) led to an increase in MDA levels when compared to the control group $(p<0.001)$, while significant decreases were observed in GSH levels $(p<0.001)$. On the other hand, MLT treatment before the MSU injection (MSU+MLT group) led to significant decreases in MDA levels $(p<0.001)$, while significant increases were observed in GSH levels $(p<0.001)$ when compared to the group without MLT treatment (MSU group). Also, the comparison of the animals that underwent PINX before MSU injection (MSU+PINX) and the animals with MLT treatment before MSU injection (MSU+MLT) revealed that MDA level increased and GSH level decreased $(p<0.001)$ in the group without MLT treatment. On the other hand, MLT treatment before MSU injection after the PINX procedure (MSU+PINX+MLT group) led to decreases in MDA levels $(p<0.001)$, while GSH levels significantly improved $(p<0.001)$ when compared to the group without MLT treatment (MSU+PINX) (Fig. 4).

\section{Comparison of Serum SOD and CAT Activities between the Groups}

It was observed that PINX procedure (PINX group) led to a significant decrease in antioxidant CAT $(p<0.01)$ and SOD $(p<0.001)$ enzyme levels when compared to the control group (Fig. 4). Furthermore, MSU injection (MSU group) led to a decrease in CAT $(p<0.005)$ and SOD $(p<0.001)$ activities when compared to the control group. On the other hand, MLT treatment before MSU injection (MSU+MLT group) led to an insignificant increase in CAT activity, while a significant increase was observed in SOD activity $(p<0.001)$ when compared to the group without MLT treatment (MSU group). The comparison of the animals that underwent PINX before MSU injection (MSU+PINX) and the animals with MLT treatment before MSU injection (MSU+MLT) demonstrated that CAT activity decreased insignificantly in the MSU+PINX group without MLT treatment, while SOD activity significantly decreased $(p<0.001)$. On the other hand, MLT treatment before MSU injection after PINX procedure (MSU+PINX+MLT group) led to no 
significant improvement in CAT activity when compared to the group without MLT treatment (MSU+PINX), while significant improvements were observed in SOD activities ( $p<0.001)$ (Fig. 4).

\section{Comparison of Serum TAS, TOS and OSI between the Groups}

PINX procedure (PINX group) led to a significant decrease in serum TAS and significant increases in TOS and OSI index when compared to the control group $(\mathrm{p}<0.001)$ (Fig. 5). Furthermore, MSU injection (MSU group) led to significant decreases in serum TAS and significant increases in TOS and OSI index when compared to the control group ( $p<0.001)$. MLT treatment before MSU injection (MSU+MLT group) led to a significant improvement in TAS $(p<0.001)$, an insignificant decrease in TOS, and a significant decrease in OSI index when compared to the group without MLT treatment (MSU group) $(p<0.001)$. The comparison of the animals that underwent PINX before MSU injection (MSU+PINX) and the animals with MLT treatment before MSU injection (MSU+MLT) revealed a significant decrease in TAS in the MSU+PINX group without MLT treatment $(p<0.005)$ and significant increases in TOS and OSI index $(p<0.001)$. On the other hand, significant increases were observed in TAS $(p<0.05)$ and significant improvements were observed in TOS and OSI index $(\mathrm{p}<0.001)$ in the group where MLT was administered after the PINX procedure and before MSU injection (MSU+PINX+MLT group) when compared to the group without MLT treatment (MSU+PINX group) (Fig. 5).

\section{Comparison of Group Serum IL-6 Levels}

PINX procedure (PINX group) led to significant increases in serum IL-6 level when compared to the control ( $p<0.001$ ), while MSU injection (MSU group) led to increases in IL-6 levels when compared to both the control $(p<0.001)$ and PINX groups $(p<0.001)$ (Fig. 6). On the other hand, MLT treatment before MSU injection (MSU+MLT group) led to a significant decrease in IL-6 level when compared to the group without MLT treatment (MSU group) $(\mathrm{p}<0.001)$. Furthermore, the comparison of the animals that underwent PINX before MSU injection (MSU+PINX) and the animals with MLT treatment before MSU injection (MSU+MLT) revealed a significant increase in IL-6 levels in the MSU+PINX group when compared to the group without MLT treatment $(p<0.001)$. The comparison of the animals that underwent PINX before MSU injection (MSU+PINX) and the animals with MLT treatment before MSU injection (MSU+MLT) revealed a significant increase in IL-6 levels in the MSU+PINX group without MLT treatment $(p<0.001)$. On the other hand, MLT treatment before MSU injection after PINX procedure (MSU+PINX+MLT group) led to a significant decrease $(p<0.01)$ in IL-6 level when compared to the group without MLT treatment (MSU+PINX) (Fig. 6).

\section{Histopathological Findings}

Control and sham groups exhibited normal histological appearances (Fig. 7A, D) and there was no significant difference between these groups $(p>0.05)$. Mild inflammation was obvious in the PINX group (Fig. 7E, F). Histopathological findings such as cartilage tissue damage, bone erosion, severe inflammatory cell infiltration and hemorrhage in the surrounding tissues, synovial membrane thickening 
were significant in the MSU group (Fig. 8A, B, C). The comparison of the control, Sham and PINX groups with the MSU group revealed a statistically significantly higher mean histopathological damage score in MSU group sections $(p<0.05)$. Histopathological changes were significantly reduced with melatonin treatment in the MSU+MLT group (Fig. 9A, B, C). The most severe damages were observed in the MSU+PINX group (Fig. 8D, E, F). The comparison of the MSU+PINX+MLT and MSU groups revealed no statistically significant difference $(p>0.05)$ (Fig. 9D, E, F). The mean histopathological damage scores are presented in Fig. 10.

\section{Discussion}

A metabolic disease, gout is characterized by inflammation induced by MSU crystal deposition due to increased serum urate concentrations [32]. Several studies reported that MSU induces the expression of several cytokines, including tumor necrosis factor-a (TNF-a), interleukin (IL)-1 $\beta$, and IL-6, leading to larger neutrophil influx into the synovium [33]. Thus, inhibiting MSU-induced neutrophil recruitment and blocking the release of inflammatory mediators may be beneficial in controlling the gout [34].

The present study aimed to determine whether the development of gout was affected by melatonin (MLT) deprivation (pinealectomy) and whether exogenous MLT administration had a protective effect against gout histologically and biochemically.

Intra-articular MSU injection is a good experimental model in rats that mimics the manifestation of gout in humans (intra-articular MSU deposition, joint redness, warmth and pain) [35]. The deposition of MSU crystals in the joints induces oxidative stress in defensive cells and leads to the release of proinflammatory mediators [36]. MLT treatment in experimental and clinical settings effectively reduced oxidative stress, also had advantages over other antioxidants since some of its metabolites are toxic species scavengers [37]. However, pinealectomy inhibits the effects of MLT. In addition to oxidative stress, it decreases cytokine and antibody concentrations in the joint, while increasing serum oxidative marker levels [38]. In a study conducted with C57B/6L mice where MSU was administered to induce acute gout inflammation, it was demonstrated that the mice paw thickness increased significantly in the model group $(P<0.01)$ when compared to the control group [39]. In another study that investigated the impact of Zisheng Shenqi decoction (ZSD) on MSU crystal-induced gouty arthritis, it was determined that swelling of the ankle was the most important symptom within the 24-hour period following MSU injection [40]. In the present study, the most prominent symptoms observed within the 24-hour post-injection period included ankle swelling and high joint temperature in the model groups (MSU group and MSU+PINX group) with intra-articular MSU injection $(20 \mathrm{mg} / \mathrm{ml})$. The presence of these symptoms indicated that the desired model was successfully created. Furthermore, it was determined that ankle swelling and high joint temperature were significantly reduced in the MSU+MLT and MSU+PINX+MLT groups treated with melatonin when compared to the model groups $(p<0.001)$, demonstrating that melatonin could inhibit the inflammation induced by MSU. 
The primary pathological characteristic of gout is the endothelial activation induced by IL-1 $\beta$, TNF- $\alpha$ and IL-6, the influx of neutrophils into the joint fluid, and the ensuing monocyte influx [41]. After the monocytes and neutrophils are activated, these cells actively phagocytose the MSU crystals, which then trigger inflammatory caspase responses. Thus, the inhibition of inflammatory cell infiltration could be an effective therapeutic strategy against gout inflammation [42]. In the present study, we observed the IL-6 levels, a prominant cytokine in gout inflammation. Serum IL-6 levels were significantly higher in the MSU injection model groups (MSU and MSU+PINX groups). In a study where the impact of rebamipidine on acute gouty arthritis was investigated in MSU-induced rats, it was reported that IL-1 $\beta$, IL-6, IL-10 and TNFa serum levels were high [43]. In another study where the effect of Polygonum cuspidatum ethanole extract on acute gouty arthritis was investigated in mice on the NLRP3/ASC/caspase-1 axis, it was reported that ankle joint swelling significantly increased in model mice, while IL-1 $\beta$, IL-6 and TNF-a expressions increased significantly [44]. In another study, it was revealed that IL-1 $\beta$ and IL- 6 mRNA expression levels were inhibited by MLT [39]. In the current study, it was determined that IL-6 levels decreased in the MSU+MLT and MSU+PINX+MLT groups treated with MLT when compared to the model groups that were not treated with MLT. MLT has quite low toxicity and adverse effects, as well as desirable properties found in ideal antioxidants. Thus, melatonin is an attractive candidate to prevent oxidation-induced damages [45].

All living organisms are constantly exposed to both endogenous and exogenous oxidizing agents. Free radical production induced by oxidative stress play a key role in the development of tissue damages and aging [46]. Phagocytosis of MSU crystals by tissue macrophages leads to the production of reactive oxygen species (ROS), inflammatory cytokines and chemokines [47]. The oxygen radicals are produced by the metabolic conversion of hypoxanthine and xanthine to uric acid, as well as neutrophil collection in the necrotic area in tissues. Subsequent reactions produce cytotoxic and oxidation products as well as lipid peroxides, including malondialdehyde (MDA) [48]. In a study where the effects of Selaginella moellendorffii in a MSU-induced gout model in rats, it was observed that plasma MDA levels increased, while the serum SOD levels decreased in the gout model group when compared to rats in the control group [49]. In another study that investigated plasma paraoxonase-1, oxidized low-density lipoprotein, and lipid peroxidation levels in gout patients, a decrease in SOD levels and an increase in MDA levels were observed in gout patients [50]. In the present study, pinealectomy (PINX group) and MSU injection (MSU group) led to significant increases in MDA levels when compared to control and sham groups. The increase in MDA levels was inducted by increased ROS and lipid peroxidation. It was also determined that lipid peroxidation and MDA levels decreased in groups treated with melatonin before injections and the procedure (MSU, PINX) due to the strong antioxidant property of the melatonin. Antioxidant enzymes such as SOD and catalase (CAT) form the main line of defense against oxidative damage. The decrease in SOD and CAT activities reflect a significant increase in free radicals, superoxide and hydrogen peroxide that lead to cellular damage [51]. In a study that investigated oxidative stress and the antioxidant effect of allopurinol in gout patients, it was reported that CAT and SOD levels were significantly lower before the treatment when compared to the control group, and these variables improved after allopurinol treatment [52]. In another study conducted with MSU-induced rats, significant decreases were observed in 
antioxidant enzymes such as SOD, CAT and GSH. In our study, pinealectomy (PINX group) and MSU injection (MSU group) led to decreases in CAT and SOD antioxidant enzyme activities when compared to the control groups. Furthermore, MLT treatment before MSU injection led to a significant increase in SOD enzyme activity, while PINX before MSU injection led to a significant decrease in SOD enzyme activity. However, the increase in CAT levels after MLT treatment before MSU injection and the decrease in CAT levels after PINX procedure before MSU injection were not statistically significant. In a study on MSUinduced gouty arthritis in mice, it was observed that MSU significantly depleted GSH [53]. In another study that investigated the effect of $15 \mathrm{~d}-\mathrm{PGJ} 2$ loaded nano capsules on pain and inflammation in MSUinduced gouty arthritis, it was reported that GSH and total antioxidant status (TAS) decreased [54]. In our study, PINX procedure and MSU injection led to a significant decrease in GSH level, which could be due to the increase in oxidative stress, indicating that GSH was depleted to overcome oxidative stress via the reaction with and neutralizing superoxide radicals. While significant increases were observed in GSH and TAS in our rat groups treated with melatonin, significant improvements were observed in total oxidant status (TOS) and oxidative stress index (OSI). Several studies emphasized that persistent MSU crystal deposition and inflammation could lead to chronic gout, which results in bone erosion, joint destruction, and significant disabilities [55].

The histopathological damage scores determined in our study revealed that MSU increased the cartilage tissue damage, bone erosion in certain regions, widespread inflammatory cell infiltration in the surrounding tissue, while melatonin significantly reduced these histopathological changes.

Decreased antioxidant capacity, increased production of free radicals, and aging increase both the prevalence and incidence of certain diseases such as gout. The protective effect of endogenous MLT in this process is manifested by the reduction in cellular damage induced by free radicals or by regulating immunity. However, in cases where endogenous MLT is insufficient, the need for exogenous MLT administration could be necessary to sustain the possible protective effects. Thus, it could be suggested that melatonin could lead to improvements in the pathological changes observed in gout due to its antioxidant and anti-inflammatory properties; and thus, it could be employed as a supplement to medical treatment. However, further clinical studies are required for more concrete evidence.

\section{Declarations}

\section{AUTHOR CONTRIBUTION}

Mehmet Demir performed experiments and drafted the manuscript. Eyup Altinoz performed experiments and analyzed data, Arwa Fadıl Haqi Ballur, Yasemin Bicer, Melike Karayakali collected samples and analyzed data. Gurkan Yigitturk, Melike Ozgul Onal, Hulya Elbe histopathological examination.

\section{FUNDING}

The research was supported by Karabuk University Scientifict Research Fund (TSA-2020-2346). 
The data used to support the findings of this study are available from the corresponding author on reasonable request.

Ethical Approval and Consent to Participate. The study was approved by the Experimental Animals Ethics Committee of Zonguldak Bulent Ecevit University, Faculty of Medicine (Protocol No: 2020-10-07/05).

Consent to publish. Not applicable

Competing Interests. The authors declare no competing interests.

\section{References}

1. Han, Q., W. Bing, Y. Di, Hua L. Shi-He, L. Yu-Hua, Z. Xiu-Guo, H. Yu-Gang, W. Qi-Ming F. and Y. Shih-Mo. 2016. Kinsenoside screening with a microfluidic chip attenuates gouty arthritis through inactivating NF-к B signaling in macrophages and protecting endothelial cells. Cell death \& disease 7: e2350e2350.

2. Choi, H. K., K. Atkinson, E. W. Karlson, W. Willett, and G. Curhan. 2004. Purine-rich foods, dairy and protein intake, and the risk of gout in men. New England Journal of Medicine 350: 1093-1103.

3. Weaver, A. L. 2008. Epidemiology of gout. Cleveland Clinic journal of medicine 75: S9-S12.

4. Schlesinger, N. 2005. Diagnosis of gout: clinical, laboratory, and radiologic findings. Am J Manag Care 11: S443-S450.

5. Ota-Kontani, A., H. Hirata, M. Ogura, Y. Tsuchiya, and M. Harada-Shiba. 2020. Comprehensive analysis of mechanism underlying hypouricemic effect of glucosyl hesperidin. Biochemical and biophysical research communications 521: 861-867.

6. Mahor, D., and G. S. Prasad. 2018. Biochemical Characterization of Kluyveromyces lactis Adenine Deaminase and Guanine Deaminase and Their Potential Application in Lowering Purine Content in Beer. Frontiers in bioengineering and biotechnology 6: 180.

7. Puig, J. G., L. Beltrán, C. M. Chew, R. Torres, D. T. Márquez, and A. P. Reino. 2016. Ultrasound in the diagnosis of asymptomatic hyperuricemia and gout. Revista Clínica Española (English Edition) 216: 445-450.

8. Rasheed, H., C. McKinney, L. K. Stamp, N. Dalbeth, R. K. Topless, R. Day, D. Kannangara, K. Williams, M. Smith, and M. Janssen. 2016. The toll-like receptor 4 (TLR4) variant rs2149356 and risk of gout in European and Polynesian sample sets. PloS one 11: e0147939.

9. So, A. 2008. Developments in the scientific and clinical understanding of gout. Arthritis research \& therapy 10: 1-6.

10. Pereira, N., M. F. Naufel, E. B. Ribeiro, S. Tufik, and H. Hachul. 2020. Influence of dietary sources of melatonin on sleep quality: a review. Journal of food science 85: 5-13. 
11. Stanciu, A. E., A. Zamfir-Chiru-Anton, M. M. Stanciu, A. P. Stoian, V. Jinga, C. Nitipir, A. Bucur, T. S. Pituru, A. L. Arsene, and C. M. Dragoi. 2020. Clinical significance of serum melatonin in predicting the severity of oral squamous cell carcinoma. Oncology letters 19: 1537-1543.

12. Ertosun, M. G., G. Kocak, and O. N. Ozes. 2019. The regulation of circadian clock by tumor necrosis factor alpha. Cytokine \& growth factor reviews 46: 10-16.

13. Luo, J., Z. Zhang, H. Sun, J. Song, X. Chen, J. Huang, X. Lin, and R. Zhou. 2020. Effect of melatonin on T/B cell activation and immune regulation in pinealectomy mice. Life sciences 242: 117191.

14. Liu, X.-W., Y. Zi, Y.-E. Liu, Y.-B. Zhang, L.-B. Xiang, and M-x Hou. 2015. Melatonin exerts protective effect on N2a cells under hypoxia conditions through Zip1/ERK pathway. Neuroscience letters 595: 74-80.

15. Yang, H. L., W. J. Zhou, C. J. Gu, Y. H. Meng, J. Shao, D. J. Li, and M. Q. Li. 2018. Pleiotropic roles of melatonin in endometriosis, recurrent spontaneous abortion, and polycystic ovary syndrome. American Journal of Reproductive Immunology 80: e12839.

16. Popa-Nita, O., and P. H. Naccache. 2010. Crystal-induced neutrophil activation. Immunol Cell Biol 88 : 32-40. doi:10.1038/icb.2009.98.

17. Ren, D-I, C. Ji, X.-B. Wang, and H. Wang, and Hu B. 2017. Endogenous melatonin promotes rhythmic recruitment of neutrophils toward an injury in zebrafish. Scientific reports 7: 1-10.

18. Xie, C., and Q. Chen. 2019. Adipokines: New therapeutic target for osteoarthritis? Current rheumatology reports 21:1-9.

19. Agudelo, C. A., and C. M. Wise. 2000. Crystal-associated arthritis in the elderly. Rheumatic Disease Clinics of North America 26: 527-546.

20. Keeble, J., F. Russell, B. Curtis, A. Starr, E. Pinter, and S. D. Brain. 2005. Involvement of transient receptor potential vanilloid 1 in the vascular and hyperalgesic components of joint inflammation. Arthritis \& Rheumatism: Official Journal of the American College of Rheumatology 52: 3248-3256.

21. Matsubara, E., T. Bryant-Thomas, J. Pacheco Quinto, T. L. Henry, B. Poeggeler, D. Herbert, F. CruzSanchez, Y. J. Chyan, M. A. Smith, and G. Perry. 2003. Melatonin increases survival and inhibits oxidative and amyloid pathology in a transgenic model of Alzheimer's disease. Journal of Neurochemistry 85: 1101-1108.

22. Öztürk, G., K. G. Akbulut, Ş Güney, and D. Acuna-Castroviejo. 2012. Age-related changes in the rat brain mitochondrial antioxidative enzyme ratios: Modulation by melatonin. Experimental gerontology 47: 706-711.

23. Coderre, T. J., and P. D. Wall. 1988. Ankle joint urate arthritis in rats provides a useful tool for the evaluation of analgesic and anti-arthritic agents. Pharmacology Biochemistry and Behavior 29: 461466.

24. Czechowska, G., K. Celinski, A. Korolczuk, G. Wojcicka, J. Dudka, A. Bojarska, and R. J. Reiter. 2015. Protective effects of melatonin against thioacetamide-induced liver fibrosis in rats. $J$ Physiol Pharmacol 66: 567-579. 
25. Ahmed, A. S., J. Li, M. Ahmed, L. Hua, T. Yakovleva, M. H. Ossipov, G. Bakalkin, and A. Stark. 2010. Attenuation of pain and inflammation in adjuvant-induced arthritis by the proteasome inhibitor MG132. Arthritis \& Rheumatism 62: 2160-2169.

26. Ohkawa, H., N. Ohishi, and K. Yagi. 1979. Assay for lipid peroxides in animal tissues by thiobarbituric acid reaction. Analytical biochemistry 95: 351-358.

27. Ellman, G. L. 1959. Tissue sulfhydryl groups. Archives of biochemistry and biophysics 82: 70-77.

28. Sun, Y., L. W. Oberley, and Y. Li. 1988. A simple method for clinical assay of superoxide dismutase. Clinical chemistry 34: 497-500.

29. Burnie, J., A. Coke, and R. Matthews. 1992. Restriction endonuclease analysis of Aspergillus fumigatus DNA. Journal of clinical pathology 45: 324-327.

30. Lowry, O. H., N. J. Rosebrough, A. L. Farr, and R. J. Randall. 1951. Protein measurement with the Folin phenol reagent. Journal of biological chemistry 193: 265-275.

31. Erel, 0. 2005. A new automated colorimetric method for measuring total oxidant status. Clinical biochemistry 38: 1103-1111.

32. Chen, H., Z.heng S Wang, Y. Zhu, H. Liu, Q. Xue, Y. Qiu, J. Zou H and X. Zhu. 2016. The effect of resveratrol on the recurrent attacks of gouty arthritis. Clinical rheumatology 35: 1189-1195.

33. Cao, Y. 2021. Icariin alleviates MSU-induced rat GA models through NF-KB/NALP3 pathway. Cell Biochemistry and Function 39: 357-366.

34. Dhanasekar, C., S. Kalaiselvan, and M. Rasool. 2015. Morin, a bioflavonoid suppresses monosodium urate crystal-induced inflammatory immune response in RAW 264.7 macrophages through the inhibition of inflammatory mediators, intracellular ROS levels and NF-KB activation. PLoS One 10: e0145093.

35. Shi, L., Z. Yuan, J. Liu, R. Cai, M. Hasnat, H. Yu, J. Feng, Z. Wang, Q. Zhao, and M. Wu. 2021. Modified Simiaowan prevents articular cartilage injury in experimental gouty arthritis by negative regulation of STAT3 pathway. Journal of Ethnopharmacology 270: 113825.

36. Bernardes, A. C. F. P. F., R. C. Matosinhos, MCdPM Araújo, C. H. Barros, RDdOA Soares, D. C. Costa, D. Sachs, and D. A. Saúde-Guimarães. 2021. Sesquiterpene lactones from Lychnophora species: Antinociceptive, anti-inflammatory, and antioxidant pathways to treat acute gout. Journal of Ethnopharmacology 269: 113738.

37. Reiter, R. J., D. X. Tan, S. Rosales-Corral, A. Galano, X. J. Zhou, and B. Xu. 2018. Mitochondria: central organelles for melatonin's antioxidant and anti-aging actions. Molecules 23: 509.

38. Jahanban-Esfahlan, R., S. Mehrzadi, R. J. Reiter, K. Seidi, M. Majidinia, H. B. Baghi, N. Khatami, B. Yousefi, and A. Sadeghpour. 2018. Melatonin in regulation of inflammatory pathways in rheumatoid arthritis and osteoarthritis: involvement of circadian clock genes. British journal of pharmacology 175: $3230-3238$.

39. Xiao, W-z, L. Zhao, L. Cao, X-x Zhu, and H-j Zou. 2021. Melatonin Alleviates Acute Gouty Inflammation In Vivo and In Vitro. Current Medical Science:1-7. 
40. Han, J., Y. Xie, F. Sui, C. Liu, X. Du, C. Liu, X. Feng, and D. Jiang. 2016. Zisheng Shenqi decoction ameliorates monosodium urate crystal-induced gouty arthritis in rats through anti-inflammatory and anti-oxidative effects. Molecular medicine reports 14: 2589-2597.

41. Cronstein, B. N., and R. Terkeltaub. 2006. The inflammatory process of gout and its treatment. Arthritis Research \& Therapy 8: 1-7.

42. Han, J., G. Shi, W. Li, S. Wang, J. Bai, X. Sun, Y. Xie, F. Sui, F. Chen, and D. Jiang. 2021. Zisheng Shenqi Decoction Ameliorates Monosodium Urate-Mediated Gouty Arthritis in Rats via Promotion of Autophagy through the AMPK/mTOR Signaling Pathway. Evidence-Based Complementary and Alternative Medicine 2021.

43. Wang, G., T. Zuo, R. Li, and Z. Zuo. 2021. Effect of rebamipide on the acute gouty arthritis in rats induced by monosodium urate crystals. Beijing da xue xue bao. Yi xue ban= Journal of Peking University. Health Sciences 53: 716-720.

44. Ma, T.-H., T. Sheng, C.-M. Tian, M.-Y. Xing, L.-J. Yan, and D.-Z. Xia. 2019. Effect of ethanolic extract of Polygonum cuspidatum on acute gouty arthritis in mice through NLRP3/ASC/caspase-1 axis. Zhongguo Zhong yao za zhi= Zhongguo zhongyao zazhi=. China journal of Chinese materia medica 44: 546-552.

45. Galano, A., and R. J. Reiter. 2018. Melatonin and its metabolites vs oxidative stress: From individual actions to collective protection. Journal of Pineal Research 65: e12514.

46. Rizzo, A. M., P. Berselli, S. Zava, G. Montorfano, M. Negroni, P. Corsetto, and B. Berra. 2010. Endogenous antioxidants and radical scavengers. Bio-Farms for Nutraceuticals, Springer, pp. 52-67.

47. Zoghebi, K. A., E. Bousoik, K. Parang, and K. A. Elsaid. 2020. Design and biological evaluation of colchicine-CD44-targeted peptide conjugate in an in vitro model of crystal induced inflammation. Molecules 25: 46.

48. Serel, T. A., F. Özguner, and S. Soyupek. 2004. Prevention of shock wave-induced renal oxidative stress by melatonin: an experimental study. Urological research 32: 69-71.

49. Zhao, P., K-I Chen, G-I Zhang, G-r Deng, and J. Li. 2017. Pharmacological basis for use of Selaginella moellendorffii in gouty arthritis: antihyperuricemic, anti-inflammatory, and xanthine oxidase inhibition. Evidence-based complementary and alternative medicine 2017.

50. Jiang, X.-L., M. Li, J.-G. Zhou, Q.-B. Yang, L.-J. Du, and J. Du. 2011. Plasma paraoxonase-1, oxidized low-density lipoprotein and lipid peroxidation levels in gout patients. Cell biochemistry and biophysics 61: 461-466.

51. Kumar, M., E. R. Kasala, L. N. Bodduluru, V. Dahiya, and M. Lahkar. 2016. Baicalein protects isoproterenol induced myocardial ischemic injury in male Wistar rats by mitigating oxidative stress and inflammation. Inflammation Research 65: 613-622.

52. Acharya, C., A. Sharma, and N. Kantharia. 2015. Involvement of oxidative stress in patients of gout and antioxidant effect of allopurinol. Int J Med Sci Public Health 4: 168-172.

53. Rossaneis, A. C., D. T. Longhi-Balbinot, M. M. Bertozzi, V. Fattori, C. Z. Segato-Vendrameto, S. BadaroGarcia, T. H. Zaninelli, L. Staurengo-Ferrari, S. M. Borghi, and T. T. Carvalho. 2019. [Ru (bpy) 2 (NO) 
SO3](PF6), a Nitric Oxide Donating Ruthenium Complex, Reduces Gout Arthritis in Mice. Frontiers in pharmacology 10: 229.

54. Ruiz-Miyazawa, K. W., L. Staurengo-Ferrari, F. A. Pinho-Ribeiro, V. Fattori, T. H. Zaninelli, S. BadaroGarcia, S. M. Borghi, K. C. Andrade, J. T. Clemente-Napimoga, and J. C. Alves-Filho. 2018. 15d-PGJ 2loaded nanocapsules ameliorate experimental gout arthritis by reducing pain and inflammation in a PPAR-gamma-sensitive manner in mice. Scientific reports 8: 1-13.

55. Voshaar, M. A. O., T. Bardin, and M. A. van de Laar. 2015. The human and economic burden of difficult-to-treat gouty arthritis. Joint bone spine 82: eS2-eS8.

\section{Figures}

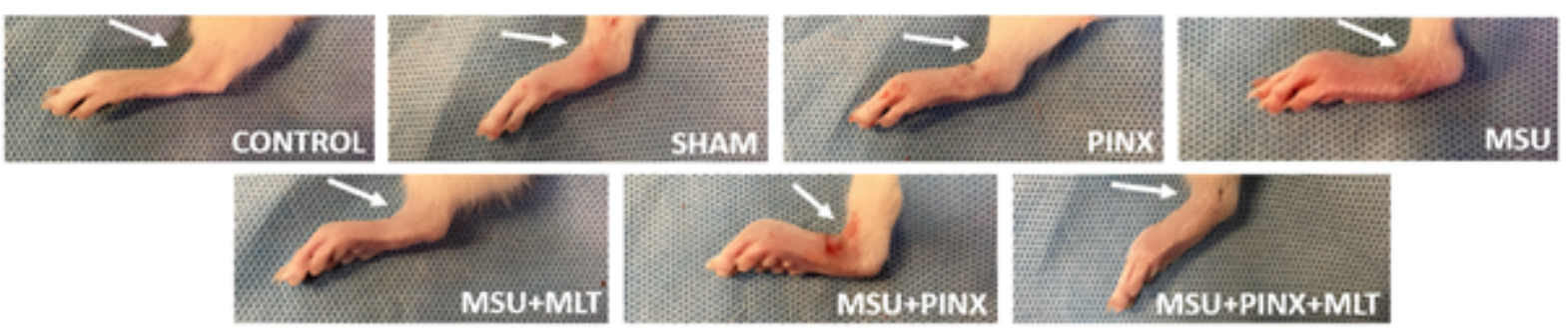

\section{Figure 1}

Effects of MLT on joint swelling induced by MSU crystal in rats. MSU crystals led to a significant increase in ankle circumference of rats compared to normal control rats. Of note, treatment with MLT (10 $\mathrm{mg} / \mathrm{kg} /$ day) significantly suppressed MSU crystal-induced ankle swelling. (Representative images of the left leg from each group are shown. Arrows indicate location of measurement). 


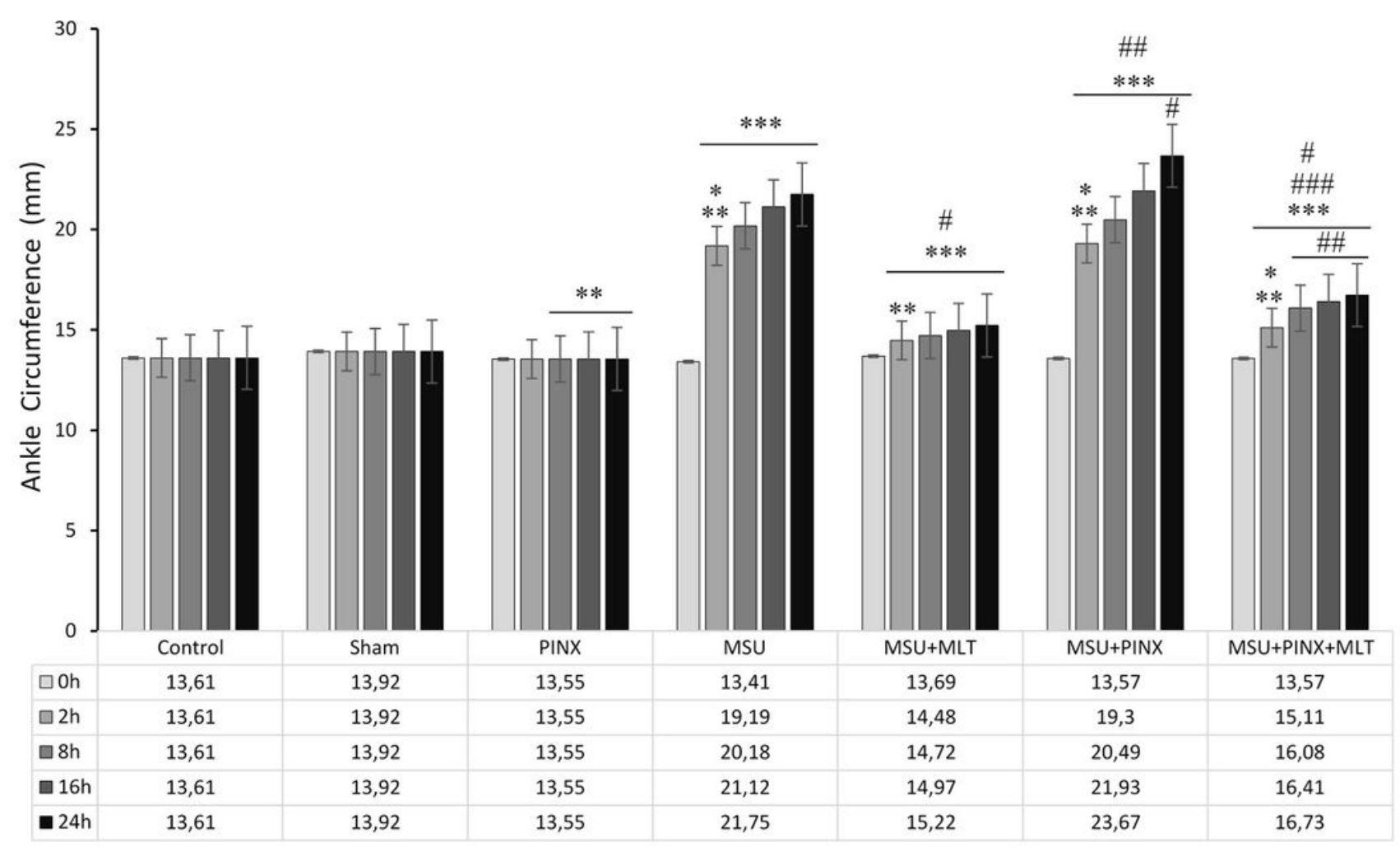

\section{Figure 2}

The mean ankle circumference of MSU-induced gout model. Data are expressed mean $\pm S E(n=8) . p<0.05$

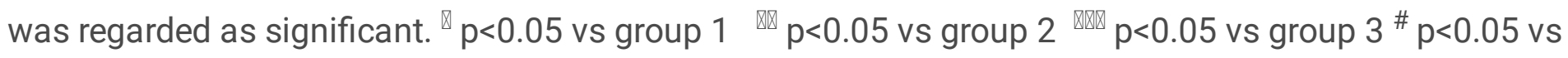
group $4{ }^{\# \#} p<0.05$ vs group $5{ }^{\# \# \#} p<0.05$ vs group 6 . 


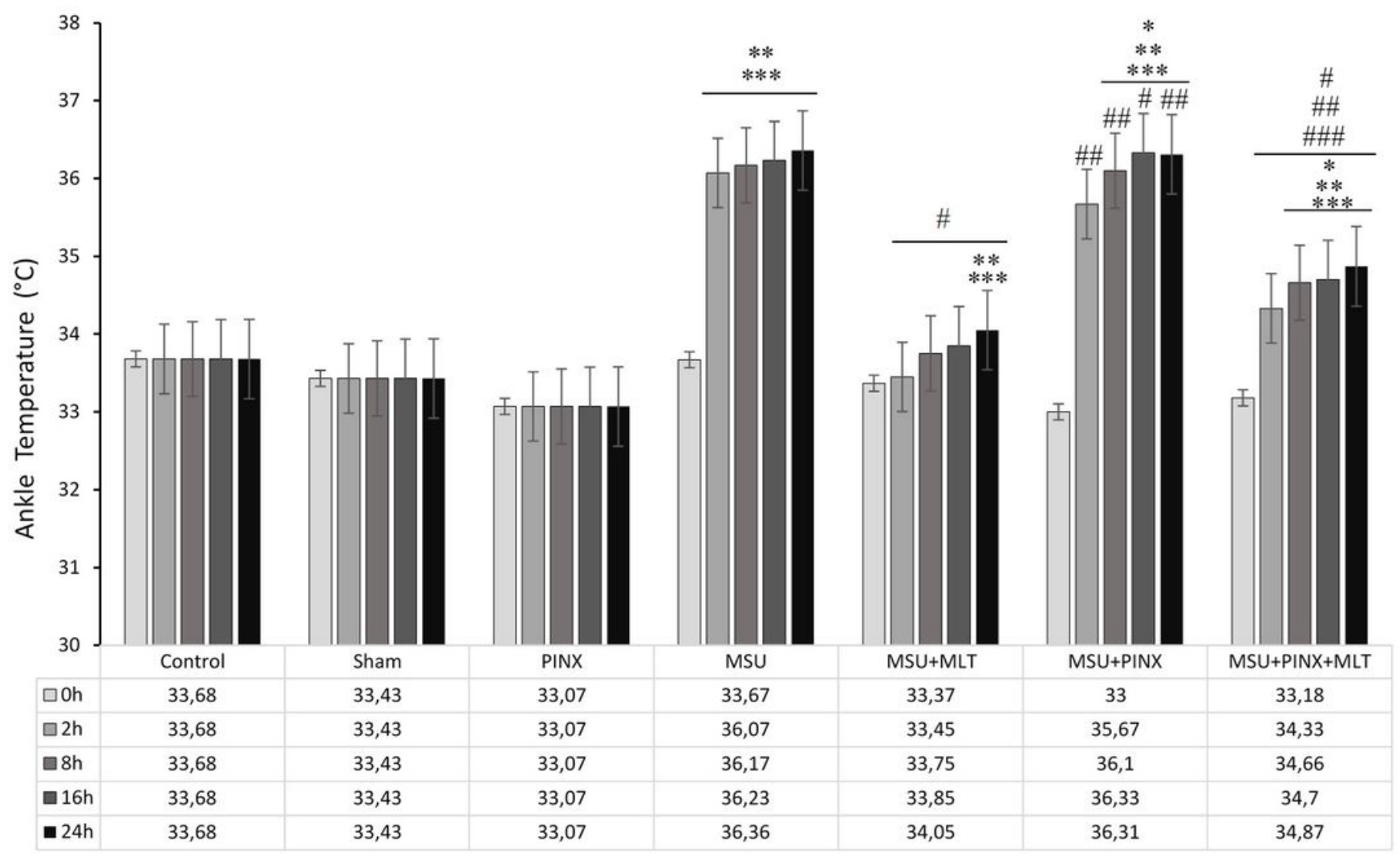

Figure 3

The mean ankle temperature of MSU-induced gout model. Data are expressed mean $\pm S E(n=8)$. $p<0.05$

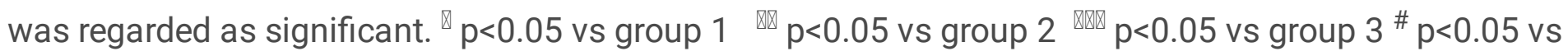
group $4{ }^{\# \#} p<0.05$ vs group $5{ }^{\# \# \#} p<0.05$ vs group. 

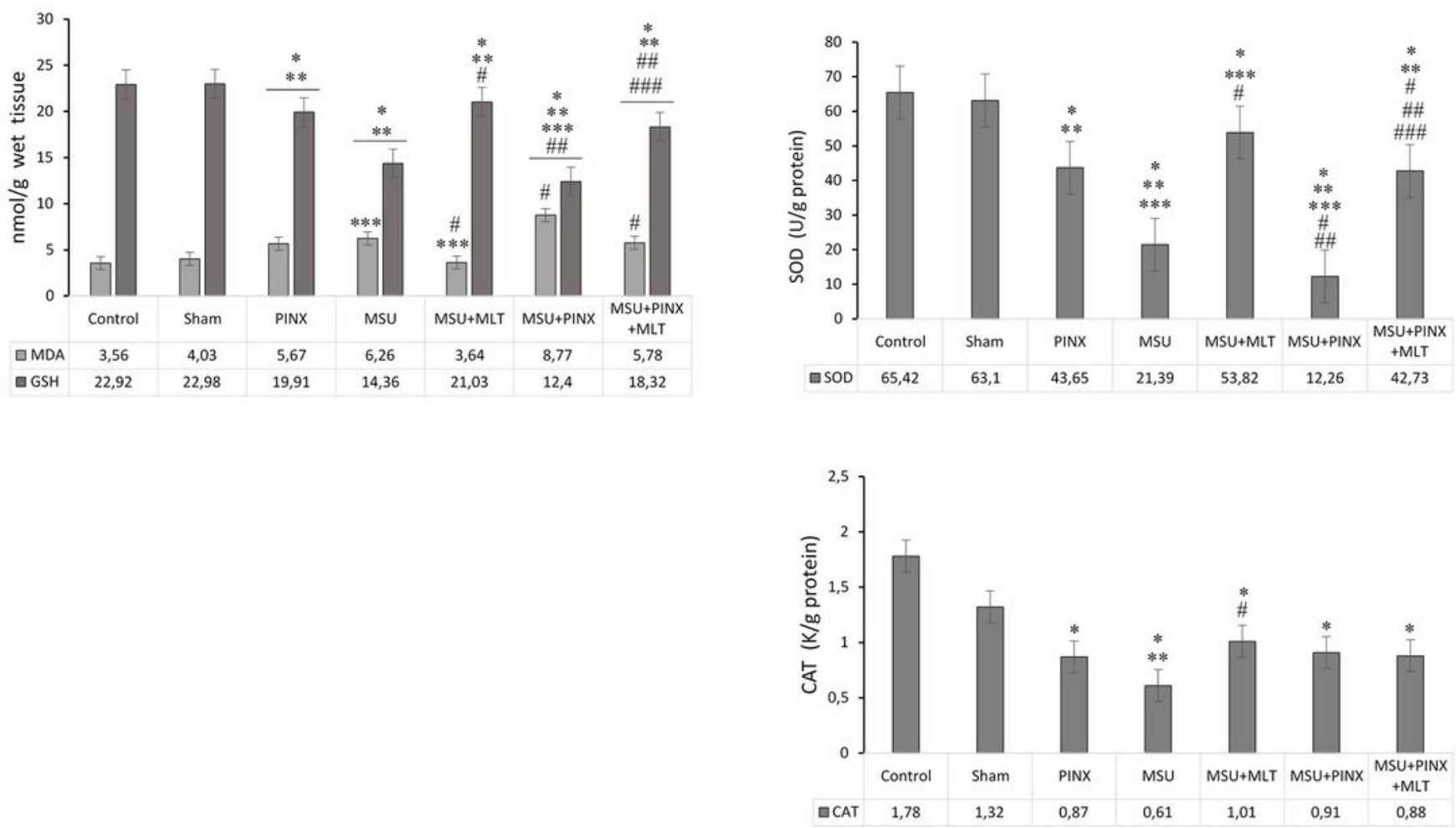

\section{Figure 4}

The mean tissue oxidant-antioxidant parameters of MSU-induced gout model. Data are expressed

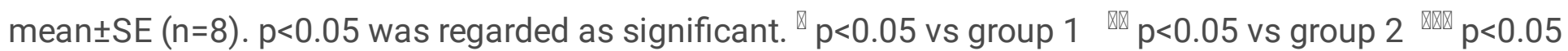
vs group $3{ }^{\#} p<0.05$ vs group $4{ }^{\# \#} p<0.05$ vs group $5{ }^{\# \# \#} p<0.05$ vs group 6. 

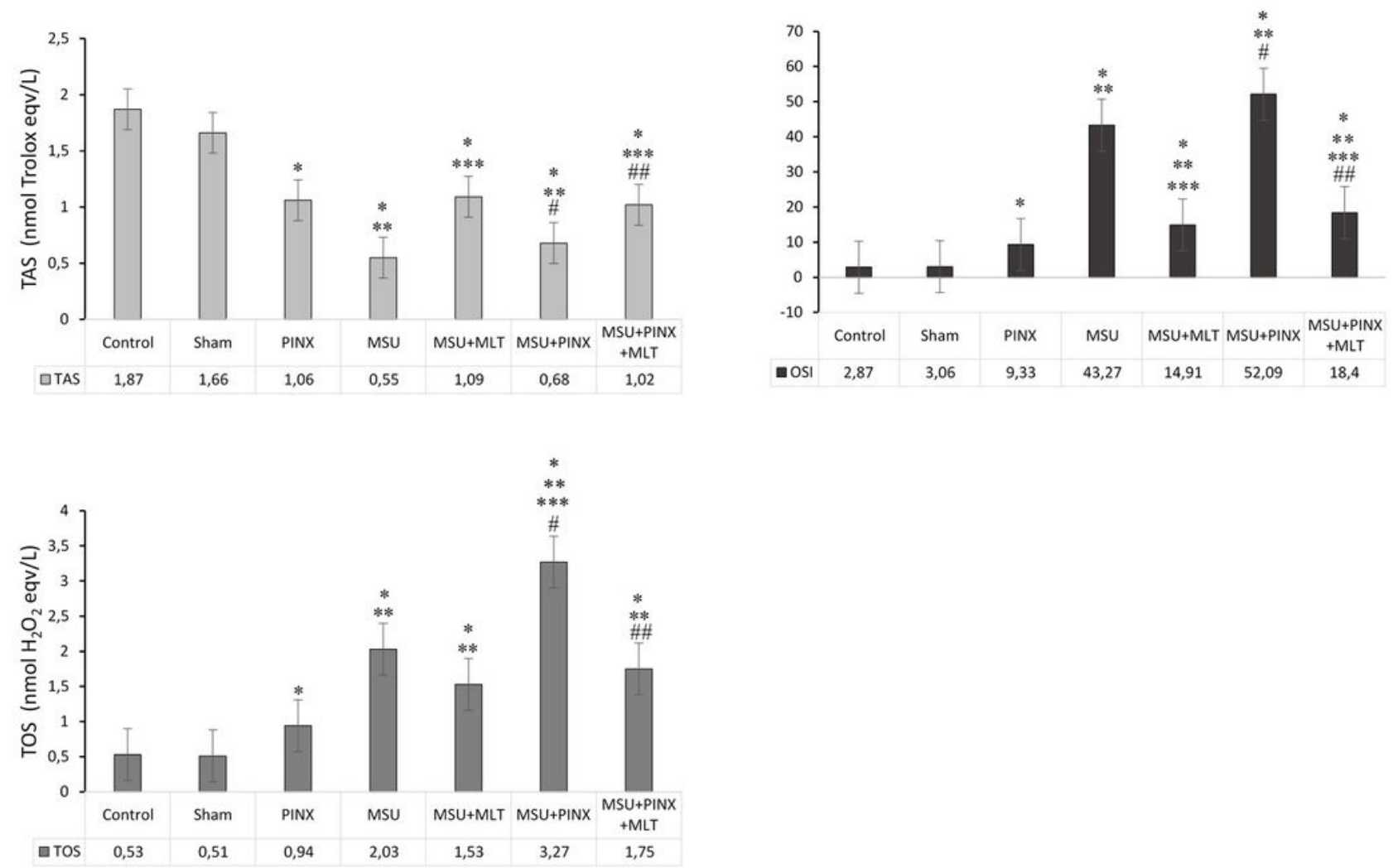

Figure 5

The mean tissue oxidant-antioxidant status of MSU-induced gout model. Data are expressed mean \pm SE

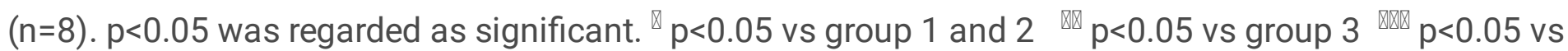
group $4{ }^{\#} p<0.05$ vs group $5{ }^{\# \#} p<0.05$ vs group 6 . 


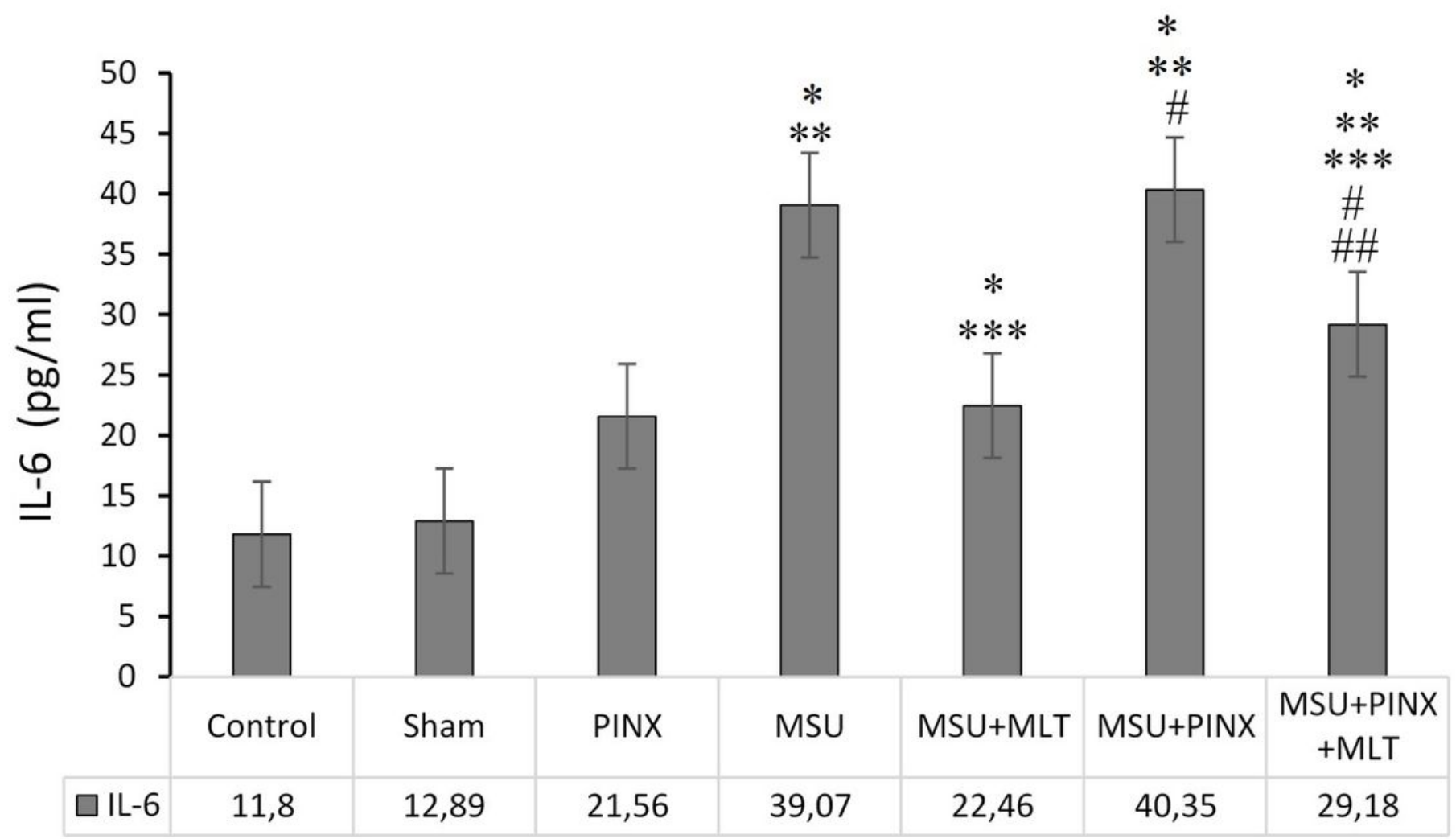

Figure 6

The mean IL-6 levels of MSU-induced gout model. Data are expressed mean $\pm S E(n=8) . p<0.05$ was

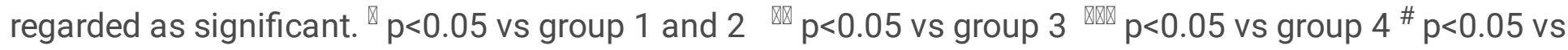
group $5{ }^{\# \#} \mathrm{p}<0.05$ vs group 6. 


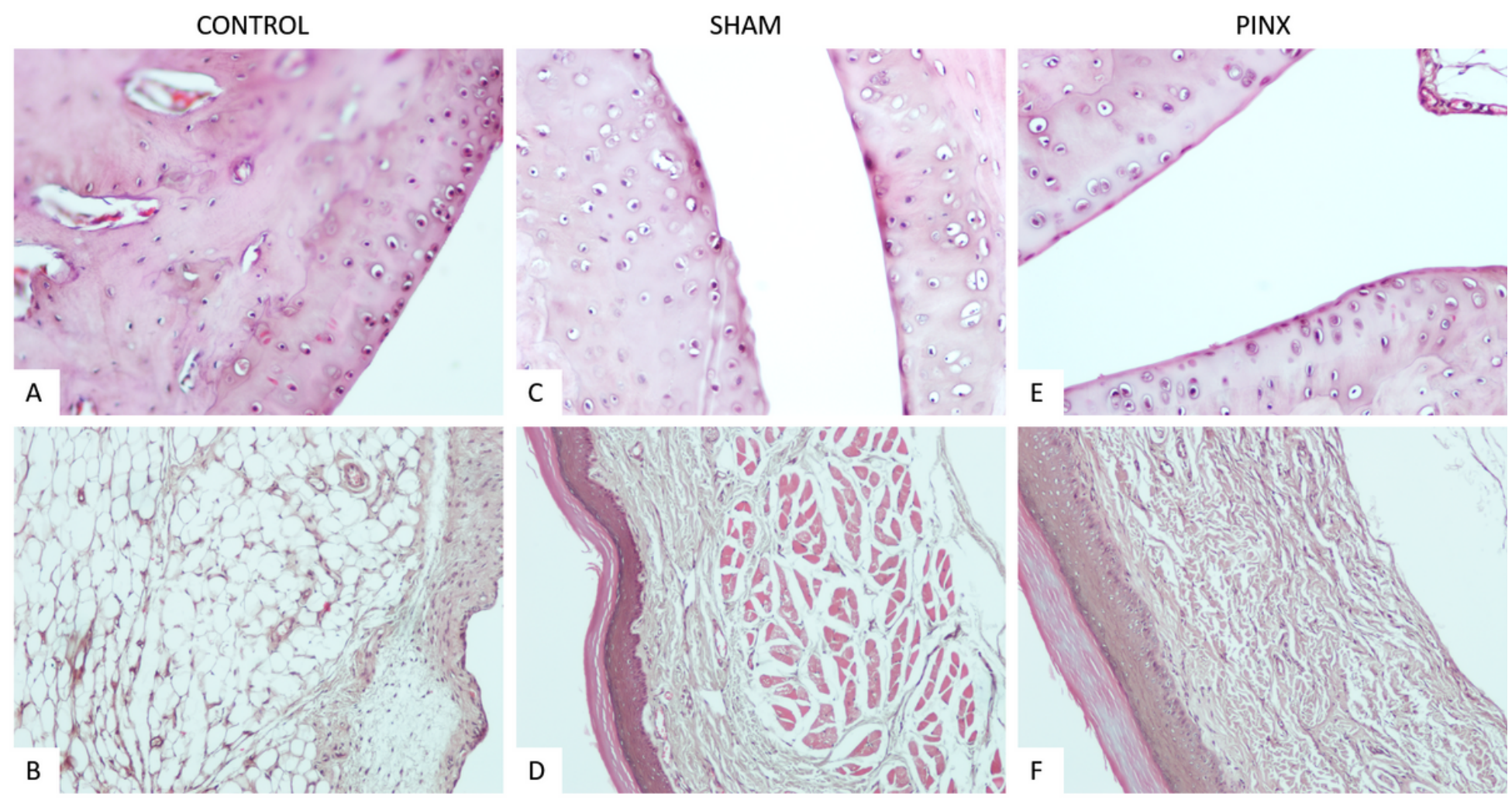

Figure 7

Control and Sham groups had normal histological appearance. Mild inflammation was seen in the PINX group. A. Control group, H-E; X20. B. Control group, H-E; X10. C. Sham group, H-E; X20. D. Sham group, HE; X10. E. PINX group, H-E; X20. F. PINX group, H-E; X10.
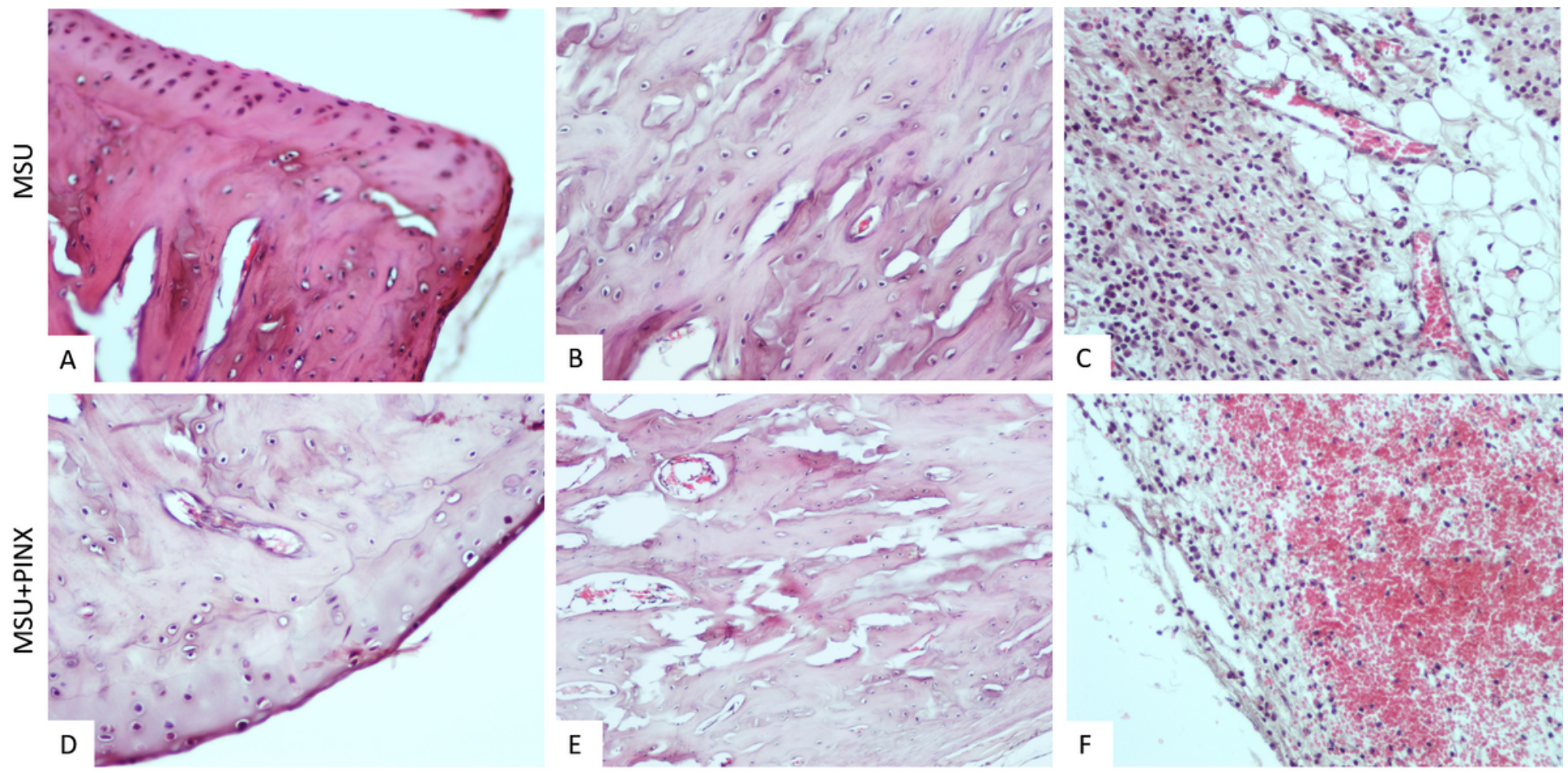


\section{Figure 8}

Histopathological findings were evident in the MSU and MSU+PINX groups. Destruction of the cartilage tissue $(A, D)$, bone erosion $(B, E)$, severe inflammatory cell infiltration and hemorrhage in the surrounding tissue (C, F), and thickening of the synovial membrane (D) were detected. The MSU+PINX group was the most severely damaged. A. MSU group, H-E; X20. B. MSU group, H-E; X20. C. MSU group, H-E; X20. D. MSU+PINX group, H-E; X20. E. MSU+PINX group, H-E; X20. F. MSU+PINX group, H-E; X20.
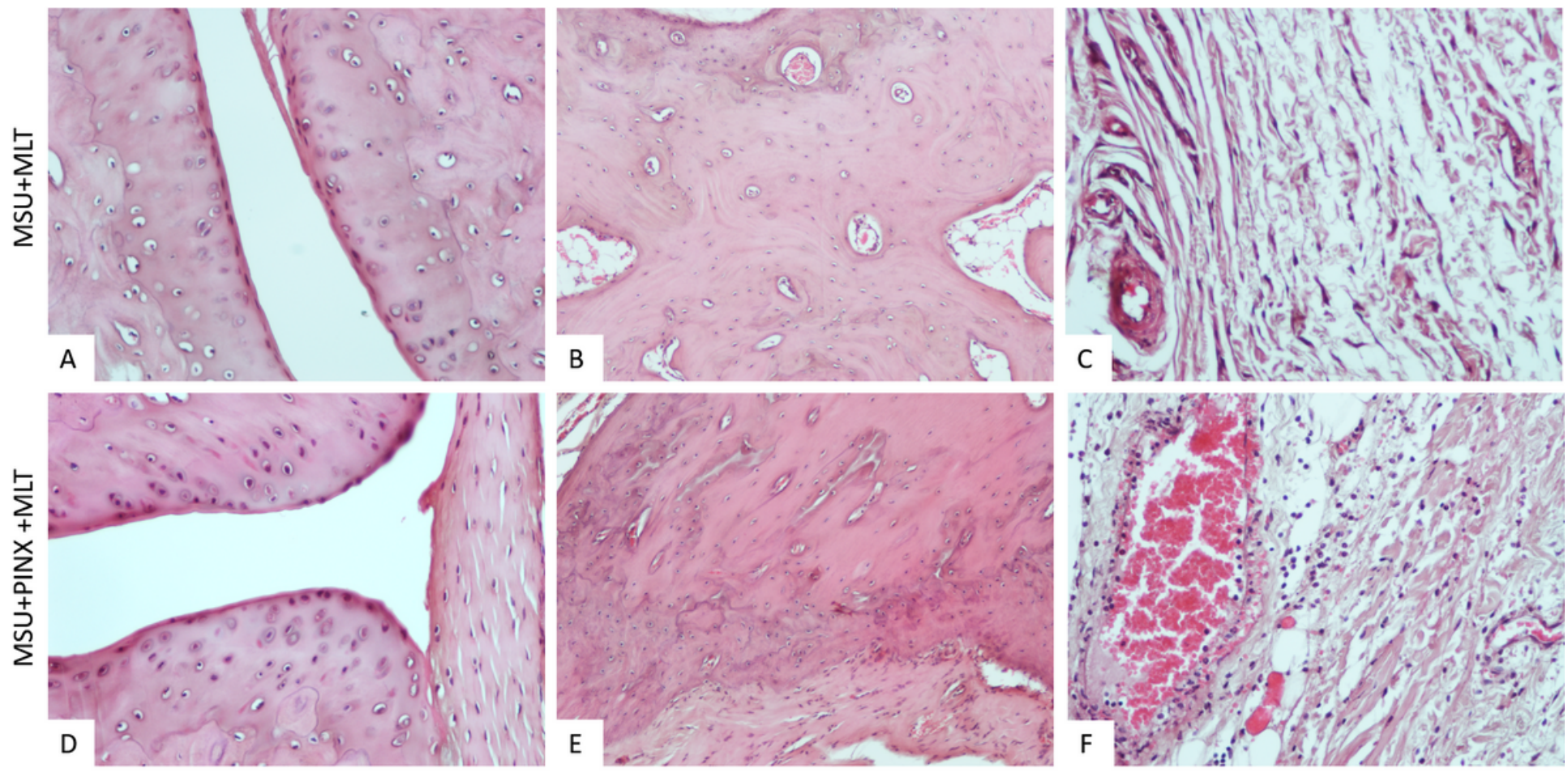

\section{Figure 9}

Histopathological changes were found to be significantly reduced in the MSU+MLT group. A. MSU+MLT group, H-E; X20. B. MSU+MLT group, H-E; X10. C. MSU+MLT group, H-E; X20. When the MSU+PINX+MLT group and MSU group were compared, there was no statistically significant difference $(p>0.05)$. $D$.

MSU+PINX+MLT group, H-E; X20. E. MSU+PINX+MLT group, H-E; X10. F. MSU+PINX+MLT group, H-E; X20. 


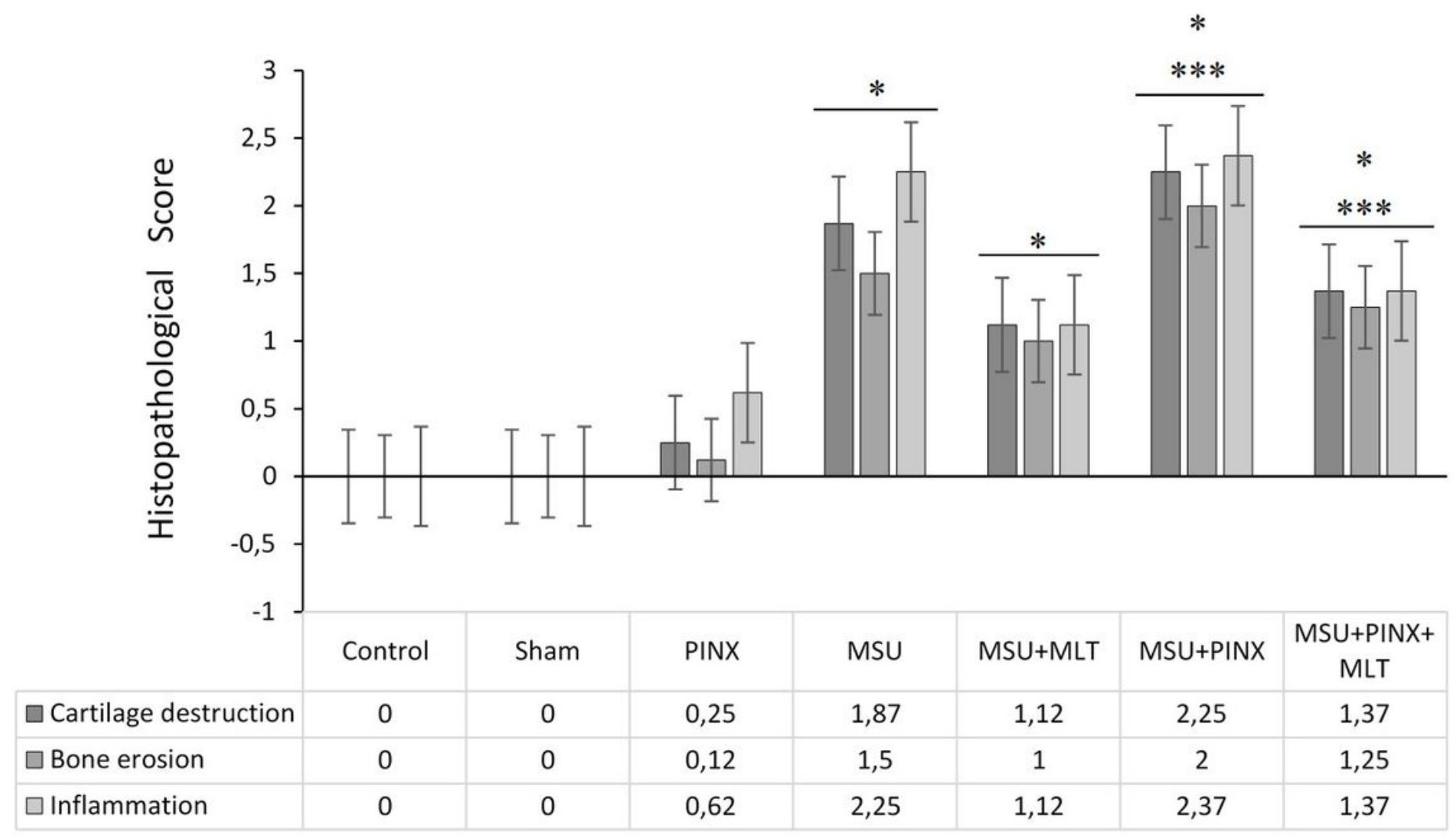

Figure 10

The mean histological damage score of MSU-induced gout model. Data are expressed mean $\pm S E(n=8)$.

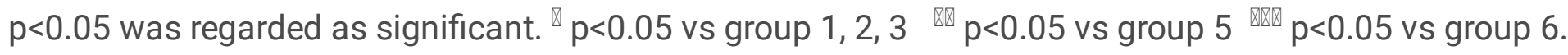

